\title{
Diffuse Midline Glioma, H3 K27M-Mutant
}

National Cancer Institute

\section{Source}

National Cancer Institute. Diffuse Midline Glioma, H3 K27M-Mutant. NCI Thesaurus. Code C129309.

A childhood diffuse midline glioma characterized by the presence of histone H3 K27M mutation. 